\title{
HUBUNGAN PERSEPSI SISWA TENTANG GURU BAHASA INDONESIA, MINAT BELAJAR, DAN MOTIVASI BELAJAR DENGAN PRESTASI BELAJAR SISWA DI MTSN SEMANU GUNUNGKIDUL
}

\author{
Muhammad Yusuf Isnaini \\ MTSN 3 Gunungkidul \\ email: yusufisnaini73@gmail.com
}

\begin{abstract}
(Title: Perceptions About Indonesian Teachers, Learning Interests, and Learning Motivation with Student Learning Achievements in MTsN Semanu Gunungkidul). Teachers have a big role in fostering positive perceptions about Indonesian language learning. This positive perception will foster interest in students to learn Indonesian seriously. The purpose of this study was to analyze the relationship between students 'perceptions of Indonesian teachers, students' interests and motivations in learning Indonesian subject matter with the learning achievements of Gunungkidul's 3 MTsN students. The correlation between students 'perceptions of Indonesian language teachers, students' interests and motivation in learning Indonesian language material with the students 'achievement in Gunungkidul's MTsN 3 is evidenced by the students' perceptions of Indonesian Language teachers (X1), which are included in quite a category $(63.10 \%)$. Student perceptions of Indonesian language teachers have a positive relationship with student learning achievement as indicated by the value of b1 of 0.413 . The relationship between students' perceptions of Indonesian teachers and student learning achievement is significant as indicated by the value of $\mathrm{t}_{\text {count }}(8,352)$ greater than $\mathrm{t}_{\text {table }}(1,960)$.
\end{abstract}

Keywords: perception, interest, motivation, learning achievement

\section{PENDAHULUAN}

Keberhasilan pembangunan membutuhkan kualitas pendidikan yang mampu memasok sumber dayamanusiayang berkompeten, salah satunya adalah dalam hal berkomunikasi baik lisan atau tulisan dengan menggunakan Bahasa Indonesia yang baik dan benar. Pembelajaran Bahasa Indonesia memungkinkan manusia untuk saling berhubungan (berkomunikasi/saling berbagi pengalaman, saling belajar dari yang lain, dan meningkatkan kemampuan intelektual. Motivasi belajar merupakan modal dasar bagi para peserta didik dalam belajar. Tanpa ada motivasi, dapat dipastikan proses belajar menjadi tidak efektif. Motivasi belajar dapat tumbuh dari dalam diri peserta didik ataupun datang dari luar dirinya. Dalam hal ini, guru dituntut dapat menumbuhkan motivasi belajar dalam diri peserta didik. Peserta didik dalam menjalankan kegiatan belajar tentu memiliki motif-motif belajar. Berdasarkan wawancara pendahuluan dengan beberapa siswa, motif-motif mereka bersifat umum dan sangat klasik yaitu motif untuk mendapatkan nilai belajar. Padahal, dalam pembelajaran berbasis kompetensi, seharusnya peserta didik memiliki kemampuan untuk memahami manfaat, maksud dan tujuan dari materi pelajaran yang akan dipelajarinya. Rendahnya motivasi belajar dan kurangnya pemahaman siswa terhadap manfaat pelajaran Bahasa Indonesia mencerminkan bagaimana persepsi peserta didik terhadap pelajaran Bahasa Indonesia.

Guru mempunyai peran besar dalam menumbuhkan persepsi yang positif tentang pelajaran Bahasa Indonesia, baik mengenai manfaat, maksud dan tujuan, daya tarik dan kesenangan yang didapat dari pelajaran Bahasa Indonesia. Persepsi positif ini akan menumbuhkan minat peserta didik untuk mempelajari Bahasa Indonesia dengan sungguh-sungguh. Sebelumnya, guru terlebih dulu harus memperlihatkan dirinya sebagai figur yang dipersepsikan secara positif oleh peserta didiknya agar tumbuh persepsi yang positif tentang pelajaran Bahasa Indonesia. Meskipun pelajaran Bahasa 
Indonesia dipandang sebagai bagian dari kehidupan seharip-hari siswa, ternyata pencapaian nilai Bahasa Indonesia tidak selalu sesuai dengan KKM.

Berdasarkan observasi pendahuluan di beberapa sekolah, khususnya di MTsN 3 Gunungkidul, banyak siswa yang menyepelekan bahasa Indonesia. Demikian pula persepsi para siswa terhadap guru Bahasa Indonesia. Selama ini banyak guru yang dipersepsikan sama dengan mata pelajaran yang diajarkan oleh guru bersangkutan. Guru matematika sering dipersepsikan sebagai guru yang menakutkan dan galak daripada guru mata pelajaran yang lainnya karena matematika dianggap sulit. Hal ini menunjukkan adanya korelasi antara persepsi peserta didik terhadap mata pelajaran dengan persepsi peserta didik terhadap guru mata pelajaran bersangkutan. Demikian pula peserta didik akan mempersepsikan guru Bahasa Indonesia Bahasa Indonesia dikaitkan dengan pelajaran Bahasa Indonesia.

Guru sebagai fasilitator peserta didik dalam pembelajaran Bahasa Indonesia perlu menampilkan diri sebagai figur yang positif. Citra guru Bahasa Indonesia perlu ditumbuhkan sebagai guru yang menarik, menyenangkan, cerdas dan sabar dalam membimbing peserta didik.

Terlepas dari berbagai faktor di atas, minat peserta didik terhadap mata pelajaran Bahasa Indonesia yang bersifat mendasar, perlu dipupuk di SMP/ MTs. Penyampaian pendidikan Bahasa Indonesia perlu dilakukan dengan cara-cara yang menarik, menyenangkan, dan tepat, sehingga memudahkan peserta didik dalam penguasai materi tersebut. Minat peserta didik terhadap pelajaran Bahasa Indonesia tumbuh seiring dengan motivasi peserta didik untuk belajar Bahasa Indonesia. Minat menunjukkan adanya keinginan atau motivasi untuk melakukan sesuatu. Dalam konteks pembelajaran Bahasa Indonesia, minat peserta didik berarti adanya keinginan peserta didik untuk mempelajari materi pelajaran Bahasa Indonesia.

Pelaksanaan pembelajaran Bahasa Indonesia di madrasah-madrasah di Kabupaten Gunungkidul belum banyak memberikan pengalaman belajar yang bermakna mengingat pembelajarannya lebih banyak dilakukan di kelas. Survei pendahuluan di beberapa SMP atau MTs di Kabupaten Gunungkidul menemukan adanya persepsi peserta didik yang beragam tentang guru Bahasa Indonesia. Beberapa peserta didik SMP dan MTs yang diwawancarai juga mengemukakan ketidaktertarikan mereka terhadap pelajaran Bahasa Indonesia. Survei pendahuluan juga menunjukkan bahwa nilai hasil belajar peserta didik pada pelajaran Bahasa Indonesia relatif masih kurang memuaskan dibandingkan dengan nilai ketuntasan minimal yang diterapkan yaitu 75 . Meskipun sudah banyak yang tuntas, tetapi angkanya tidak jauh-jauh dari 75 .

Pembelajaran Bahasa Indonesia di MTsN 3 Gunungkidul kurang mendapatkan dukungan sarana pembelajaran di sekolah. Di sekolah hanya ada perpustakaan yang tanpa ada jaringan internet. Laboratorium bahasa tidak tersedia sehingga guru harus ekstra dalam pembelajaran guna meningkatkan minat dan motivasi siswa terhadap pelajaran Bahasa Indonesia.

\section{METODE}

Penelitian dilaksanakan di MTsN 3 Gunungkidul, sekolah tersebut dipakai sebagai lokasi penelitian karena merupakan sekolah tempat peneliti mengajar sekarang ini. Subyek Penelitian ini ialah seluruh siswa kelas VIII MTsN 3 Gunungkidul di Kabupaten Gunungkidul yang jumlahnya ada 168 anak

Obyek penelitian ini ialah persepsi siswa terhadap guru Bahasa Indonesia, minat dan motivasi siswa MTsN dalam mempelajari materi pelajaran Bahasa Indonesia dengan prestasi belajar MTsN 3 Gunungkidul.

Data primer yang dibutuhkan adalah data yang berkenaan dengan persepsi siswa, data tentang minat siswa terhadap pelajaran Bahasa Indonesia, data tentang motivasi belajar siswa, dan data tentang prestasi belajar siswa. Data primer ini diperoleh melalui kuesioner dan test tertulis. Data sekunder yang dibutuhkan dalam penelitian ini adalah datadata yang didapat dari hasil-hasil penelitian sejenis, kepustakaan atau sumber tertulis lainnya yang menginformasikan pembelajaran Bahasa Indonesia di lokasi penelitian. Metode yang 
digunakan untuk mengumpulkan data yaitu: 1. Metode dokumentasi yaitu metode dokumentasi adalah usaha mencari data mengenai keadaan siswa dan guru. Dokumentasi yang dimaksud adalah notulen, daftar hadir, makalah, dan lain-lain sebagai bukti fisik kegiatan pembelajaran Bahasa Indonesia MTsN $3 \mathrm{Gu}-$ nungkidul. 2. Metode Angket yaitu angket atau kuesioner merupakan instrumen penelitian untuk mengumpulkan data tentang identitas responden, persepsi siswa, minat siswa, motivasi siswa untuk mempelajari Bahasa Indonesia, dan prestasi belajar Bahasa Indonesia. 3. Tes tertulis merupakan tes untuk mengetahui kemampuan siswa dalam menguasai materi pelajaran Bahasa Indonesia. Tes dilakukan dengan memberikan sejumlah soal Bahasa Indonesia sesuai dengan kurikulum pelajaran Bahasa Indonesia semester 2. Teknik analisis data adalah suatu cara yang dilakukan untuk mengolah data agar dihasilkan suatu kesimpulan yang tepat. Analisis data yang dilakukan dalam penelitian ini meliputi analisis deskriptif dan uji hipotesis dengan menggunakan regresi tiga prediktor.

\section{HASIL DAN PEMBAHASAN \\ Persepsi Siswa $\left(\mathbf{X}_{1}\right)$}

Sampel penelitian sebanyak 168 responden sehingga dalam penyajian data mengikuti persamaan dari Sturges (Riduwan, 2011) sebagai berikut:

$$
\begin{aligned}
\mathrm{K} & =1+3,3 \log \mathrm{N} \\
& =1+3,3 \log 168 \\
& =8,34 \text { dibulatkan } 8
\end{aligned}
$$

Data penelitian persepsi siswa diatas dapat dibuat distribusi frekuensi sebagaimana disajikan pada Tabel 1.

Tabel 1. Distribusi Frekuensi Variabel Persepsi Siswa

\begin{tabular}{cccc}
\hline No & Interval & Frekuensi (F) & Prosentase (\%) \\
\hline 1 & $20-28$ & 4 & 2,38 \\
2 & $29-37$ & 11 & 6,55 \\
3 & $38-46$ & 34 & 20,24 \\
4 & $47-55$ & 43 & 25,60 \\
5 & $56-64$ & 33 & 19,64 \\
6 & $65-73$ & 30 & 17,86 \\
7 & $74-82$ & 5 & 2,98 \\
8 & $83-92$ & 8 & 4,76 \\
\hline \multicolumn{5}{c}{ Jumlah } & 168 & 100,00 \\
\hline
\end{tabular}

Berdasarkan interval data penelitian persepsi siswa dapat dilihat bahwa interval paling banyak adalah $47-55$, yaitu 43 responden.

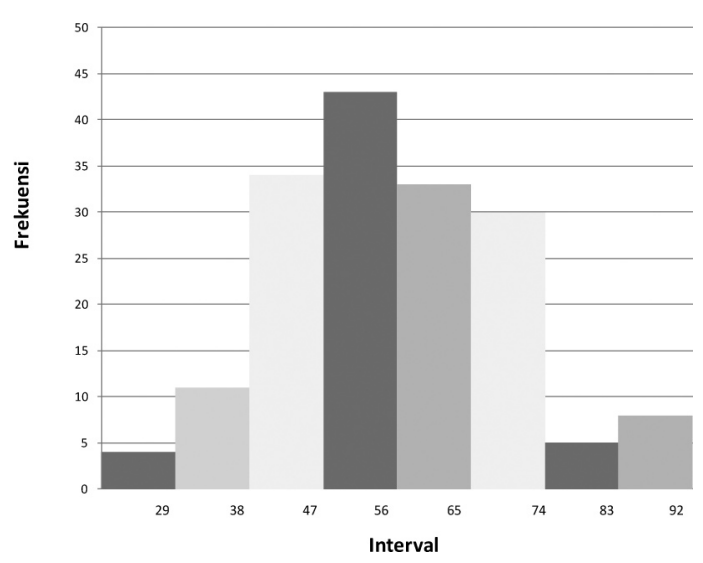

Gambar 1. Grafik Variabel Persepsi Siswa

Item pertanyaan yang digunakan untuk mengukur persepsi siswa terhadap Guru Bahasa Indonesia terdiri atas 20 pertanyaan. Mean ideal $(\mu)$ dan standard deviasi ideal $(\sigma)$ dapat dihitung dengan persamaan berikut ini (Azwar, 2010).

Skor maksimum $=20 \times 5=100$

Skor minimum $=20 \times 1=20$

Mean ideal $(\sigma)=$

$\frac{\text { Skor maksimum }+ \text { Skor minimum }}{2}$

$$
=\frac{100+20}{2}=60
$$

Standar deviasi ideal $(\sigma)=$

Skor maksimum - Skor minimum

$$
=\frac{100-20}{6}=13,33
$$

Kategori ditentukan sebagai berikut (Azwar, 2010).

Baik $=(\mu+1 \sigma)$ sampai 100

$=73,33$ sampai 100

Cukup $=(\mu-1 \sigma)$ sampai $(\mu+1 \sigma)$

$=46,67$ sampai 73,33

Kurang $=10$ sampai $(\mu-1 \sigma)$

$=10$ sampai 46,67 
Distribusi frekuensi dari variabel persepsi siswa terhadap guru bahasa Indonesia dapat dilihat pada Tabel 2.

Tabel 2. Kategori Variabel Persepsi Siswa

\begin{tabular}{lcc}
\hline \multicolumn{1}{c}{ Kategori } & Frekuensi (F) & Prosentase (\%) \\
\hline Baik & 13 & 7,74 \\
Cukup & 106 & 63,10 \\
Kurang & 49 & 29,17 \\
\hline Total & 168 & 100,00 \\
\hline
\end{tabular}

Berdasarkan tabel 2 dapat diketahui bahwa variabel persepsi siswa terhadap guru bahasa Indonesia terbanyak dalam kategori cukup $(63,10 \%)$, kemudian diikuti kurang $(29,17 \%)$ dan terakhir baik $(7,74 \%)$.

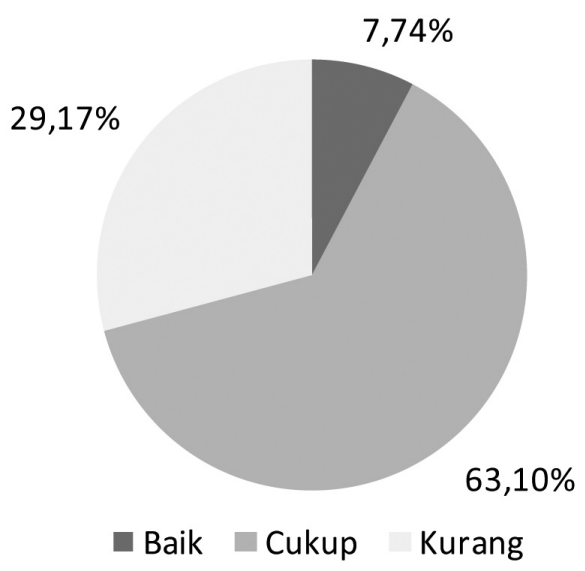

Gambar 2. Grafik Kategori Persepsi Siswa

\section{Minat Belajar Siswa $\left(\mathbf{X}_{2}\right)$}

Data penelitian minat belajar siswa diatas dapat dibuat distribusi frekuensi sebagaimana disajikan pada Tabel 3 .

Tabel 3. Distribusi Frekuensi Minat Belajar Siswa

\begin{tabular}{cccc}
\hline No & Interval & Frekuensi (F) & Prosentase (\%) \\
\hline 1 & $16-22$ & 4 & 2,38 \\
2 & $23-29$ & 3 & 1,79 \\
3 & $30-36$ & 48 & 28,57 \\
4 & $37-43$ & 38 & 22,62 \\
5 & $44-50$ & 37 & 22,02 \\
6 & $51-57$ & 27 & 16,07 \\
7 & $58-64$ & 6 & 3,57 \\
8 & $65-72$ & 5 & 2,98 \\
\hline & Jumlah & 168 & 100,00 \\
\hline
\end{tabular}

Apabila dilihat dari interval data penelitian minat belajar siswa dapat dilihat bahwa interval paling banyak adalah $30-36$, yaitu 48 responden.

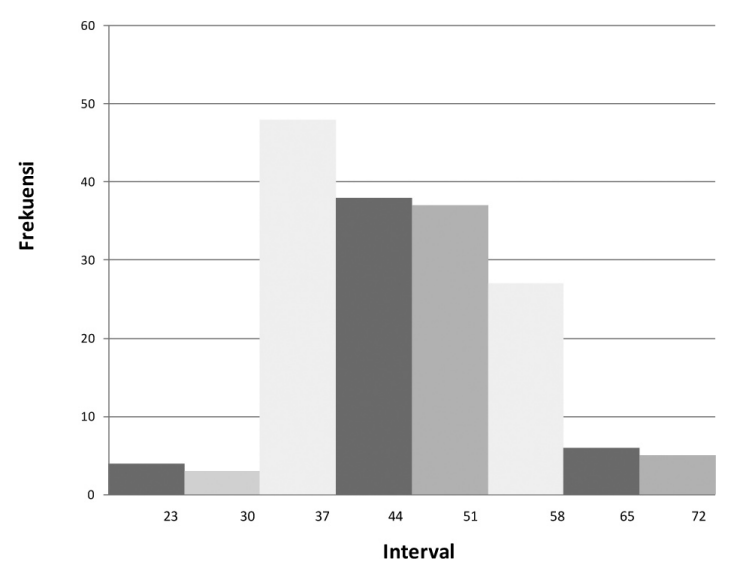

Gambar 3. Grafik Variabel Minat Belajar Siswa

Item pertanyaan yang digunakan untuk mengukur minat belajar siswa terdiri atas 20 pertanyaan. Mean ideal $(\mu)$ dan standard deviasi ideal $(\sigma)$ dapat dihitung dengan persamaan berikut ini (Azwar, 2010).

Skor maksimum $=16 \times 5=80$

Skor minimum $=16 \times 1=16$

Mean ideal $(\sigma)=$

$\frac{\text { Skor maksimum }+ \text { Skor minimum }}{2}$

Standar deviasi ideal $(\sigma) \stackrel{2}{=}$

$$
=\frac{80+16}{\stackrel{2}{=}}=48
$$

$\underline{\text { Skor maksimum - Skor minimum }}$

$$
=\frac{80-16}{6}=10,67
$$

Kategori ditentukan sebagai berikut (Azwar, 2010):

Baik $=(\mu+1 \sigma)$ sampai 80

$=58,67$ sampai 80

Cukup $=(\mu-1 \sigma)$ sampai $(\mu+1 \sigma)$

$=37,33$ sampai 58,67

Kurang $=16$ sampai $(\mu-1 \sigma)$

$=16$ sampai 37,33

Hubungan Persepsi Siswa tentang Guru Bahasa Indonesia ... (Muhammad Yusuf Isnaini) 
Distribusi frekuensi dari variabel minat belajar siswa terhadap bahasa Indonesia dapat dilihat pada tabel 4:

Tabel 4. Kategori Minat belajar Siswa

\begin{tabular}{ccc}
\hline Kategori & Frekuensi $(\mathrm{F})$ & Prosentase $(\%)$ \\
\hline Baik & 9 & 5,36 \\
Cukup & 95 & 56,55 \\
Kurang & 64 & 38,10 \\
\hline Total & 168 & 100,00 \\
\hline
\end{tabular}

Berdasarkan tabel di atas dapat diketahui bahwa variabel minat belajar siswa terhadap bahasa Indonesia terbanyak dalam kategori cukup (56,55\%), kemudian diikuti kurang $(38,10 \%)$ dan terakhir baik $(5,36 \%)$.

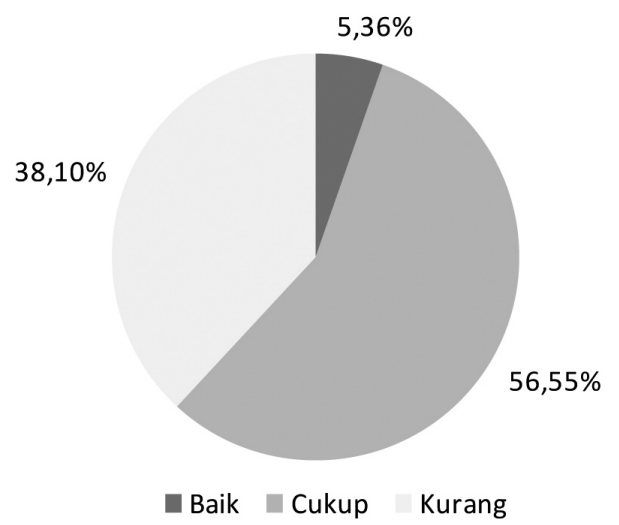

Gambar 4. Grafik Kategori Minat Belajar Siswa

\section{Motivasi Belajar $\left(\mathbf{X}_{3}\right)$}

Data penelitian motivasi belajar siswa diatas dapat dibuat distribusi frekuensi disajikan pada Tabel 5.

Tabel 5. Distribusi Frekuensi Motivasi Belajar Siswa

\begin{tabular}{cccc}
\hline No & Interval & Frekuensi (F) & Prosentase (\%) \\
\hline 1 & $26-35$ & 3 & 1,79 \\
2 & $36-45$ & 3 & 1,79 \\
3 & $46-55$ & 52 & 30,95 \\
4 & $56-65$ & 50 & 29,76 \\
5 & $66-75$ & 36 & 21,43 \\
6 & $76-85$ & 12 & 7,14 \\
7 & $86-95$ & 8 & 4,76 \\
8 & $96-106$ & 4 & 2,38 \\
\hline & Jumlah & 168 & 100,00 \\
\hline
\end{tabular}

Apabila dilihat dari interval data penelitian motivasi belajar siswa dapat dilihat bahwa interval paling banyak adalah $46-55$, yaitu 52 responden.

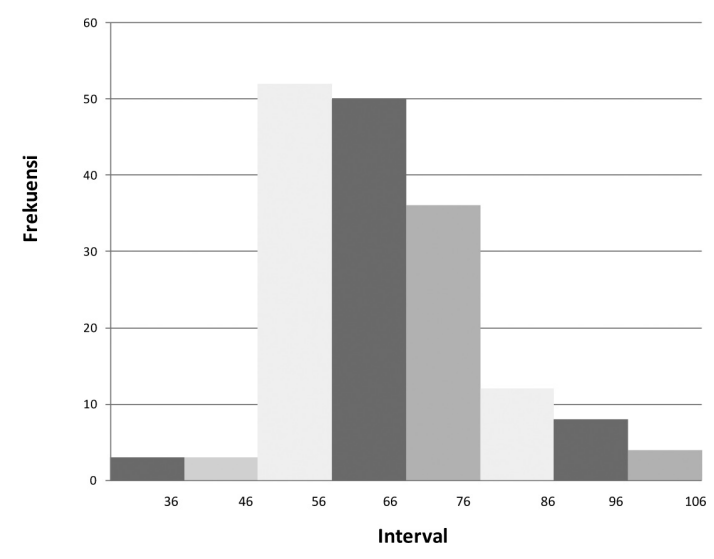

Gambar 5. Grafik Variabel Motivasi Belajar Siswa

Item pertanyaan yang digunakan untuk mengukur motivasi belajar siswa terdiri atas 22 pertanyaan. Mean ideal $(\mu)$ dan standard deviasi ideal dapat dihitung dengan persamaan berikut.

Skor maksimum $=22 \times 5=110$

Skor minimum $=22 \times 1=22$

Mean ideal $(\sigma)=$

$\frac{\text { Skor maksimum }+ \text { Skor minimum }}{2}$

$$
=\frac{110+22}{2}=66
$$

Standar deviasi ideal $(\sigma)=$

$\frac{\text { Skor maksimum - Skor minimum }}{6}$

$$
=\frac{110-22}{6}=14,67
$$

Kategori ditentukan sebagai berikut:

$$
\begin{aligned}
\text { Baik } & =(\mu+1 \sigma) \text { sampai } 110 \\
& =80,67 \text { sampai } 110 \\
\text { Cukup } & =(\mu-1 \sigma) \text { sampai }(\mu+1 \sigma) \\
& =51,33 \text { sampai } 80,67 \\
\text { Kurang } & =22 \text { sampai }(\mu-1 \sigma) \\
& =22 \text { sampai } 51,33
\end{aligned}
$$

Distribusi frekuensi dari variabel motivasi belajar siswa terhadap bahasa Indonesia dapat dilihat pada tabel berikut ini. 
Tabel 6. Kategori Variabel Motivasi Belajar Siswa

\begin{tabular}{lcc}
\hline \multicolumn{1}{c}{ Kategori } & Frekuensi (F) & Prosentase (\%) \\
\hline Baik & 17 & 10,12 \\
Cukup & 125 & 74,40 \\
Kurang & 26 & 15,48 \\
\hline Total & 168 & 100,00 \\
\hline
\end{tabular}

Berdasarkan Tabel 6 dapat diketahui bahwa variabel motivasi belajar siswa terhadap Bahasa Indonesia terbanyak dalam kategori cukup (74,40\%), kemudian diikuti kurang $(15,48 \%)$ dan terakhir baik $(10,12 \%)$.

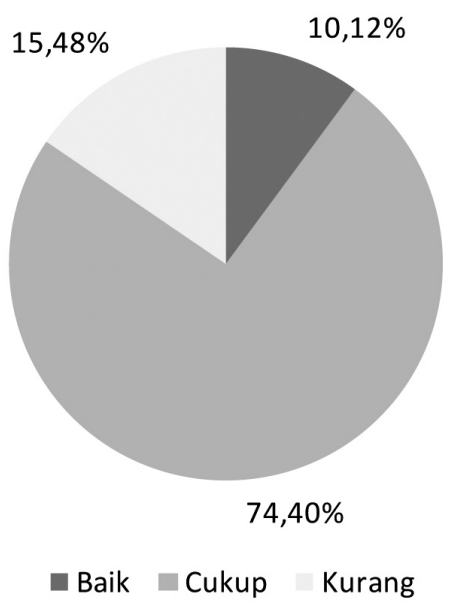

Gambar 6. Grafik Kategori Motivasi Belajar Siswa

\section{Prestasi Belajar (Y)}

Data penelitian prestasi belajar siswa diatas dapat dibuat distribusi frekuensi sebagaimana disajikan pada Tabel 7.

Tabel 7. Distribusi Frekuensi Prestasi Belajar Siswa

\begin{tabular}{cccc}
\hline No & Interval & Frekuensi (F) & Prosentase (\%) \\
\hline 1 & $30-37$ & 3 & 1,79 \\
2 & $38-45$ & 21 & 12,50 \\
3 & $46-53$ & 15 & 8,93 \\
4 & $54-61$ & 69 & 41,07 \\
5 & $62-69$ & 20 & 11,90 \\
6 & $70-77$ & 32 & 19,05 \\
7 & $78-85$ & 7 & 4,17 \\
8 & $86-94$ & 3 & 0,60 \\
\hline \multicolumn{5}{c}{ Jumlah } & 168 & 100,00 \\
\hline
\end{tabular}

Apabila dilihat dari interval data penelitian prestasi belajar siswa dapat dilihat bahwa interval paling banyak adalah $54-61$ yaitu 69 responden.

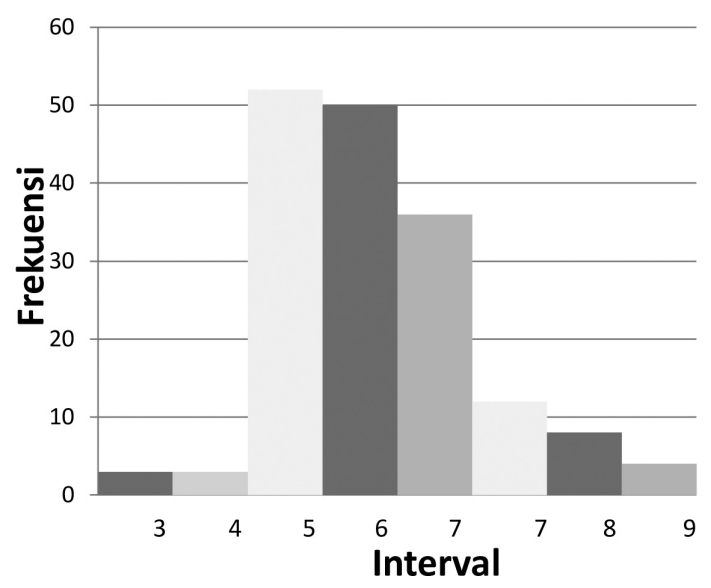

Gambar 7. Grafik Variabel Prestasi Belajar Siswa

Prestasi belajar diukur dengan tes yang telah dilakukan dan hasilnya adalah sebagai berikut.

Skor maksimum $=90$

Skor minimum $=30$

Mean ideal $(\sigma)=$

$\frac{\text { Skor maksimum }+ \text { Skor minimum }}{2}$

$$
=\frac{90+30}{2}=60
$$

Standar deviasi ideal $(\sigma)=$

$\underline{\text { Skor maksimum - Skor minimum }}$

$$
=\frac{90-30}{6}=10,00
$$

Kategori ditentukan sebagai berikut:

Baik $=(m+1 \sigma)$ sampai 90

$=70,00$ sampai 90

Cukup $=(\mu-1 \sigma)$ sampai $(\mu+1 \sigma)$

$=50,00$ sampai 70,00

Kurang $=30$ sampai $(\mu-1 \sigma)$

$=30$ sampai 50,00

Distribusi frekuensi dari variabel prestasi belajar siswa terhadap bahasa Indonesia dapat dilihat pada tabel berikut ini: 
Tabel 8. Kategori Variabel Prestasi Belajar Siswa

\begin{tabular}{lcc}
\hline \multicolumn{1}{c}{ Kategori } & Frekuensi (F) & Prosentase (\%) \\
\hline Baik & 40 & 23,81 \\
Cukup & 104 & 61,90 \\
Kurang & 24 & 14,29 \\
\hline Total & 168 & 100,00 \\
\hline
\end{tabular}

Berdasarkan Tabel 8 dapat diketahui bahwa variabel prestasi belajar siswa bahasa Indonesia terbanyak dalam kategori cukup $(61,90 \%)$, kemudian diikuti baik $(23,81 \%)$ dan terakhir kurang $(14,29 \%)$.

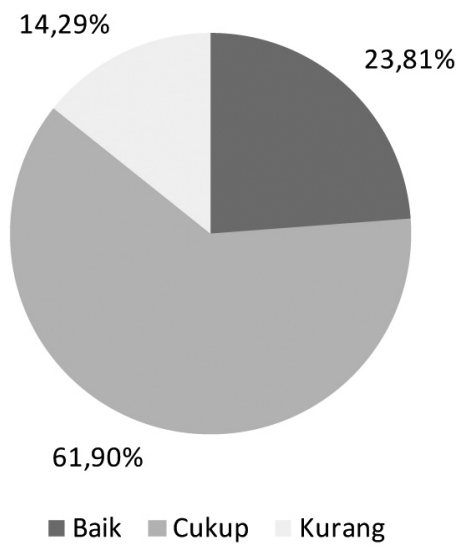

Gambar 8. Grafik Kategori Prestasi Belajar Siswa

Prestasi belajar bahasa Indonesia siswa semester 2 kelas VIIIMTsN 3 Gunungkidul sebagian besar termasuk dalam kategori cukup $(61,90 \%)$. Penelitian ini juga menunjukkan bahwa prestasi belajar siswa ini dipengaruhi oleh persepsi siswa, minat belajar siswa dan motivasi belajar baik secara parsial maupun simultan. Besarnya pengaruh ketiga variabel ini sebesar 45,9\%.

Pertama, persepsi siswa terhadap guru Bahasa Indonesia sebagian besar termasuk dalam kategori cukup $(63,10 \%)$. Persepsi siswa berpengaruh positif $\left(b_{1}=0,413\right)$ dan signifikan $\left(\mathrm{t}_{\text {hitung }}>\mathrm{t}_{\text {tabe }}\right)$ terhadap prestasi belajar siswa. Apabila persepsi siswa terhadap guru Bahasa Indonesia bertambah baik maka prestasi belajar siswa juga baik begitu pula sebaliknya apabila persepsi siswa terhadap guru Bahasa Indonesia kurang baik maka prestasi belajar juga kurang.
Persepsi sendiri adalah proses mengenal dan mamahami orang lain, jika persepsi yang dimiliki siswa baik, maka prestasinya dapat menjadi baik. Kecakapan dan keterampilan guru merupakan salah satu komponen dalam proses belajar mengajar yang ikut mempengaruhi persepsi siswa. Persepsi terhadap suatu objek akan berbeda pada masing-masing individu tergantung pada pengalamannya, proses belajar, sosialisasi, cakrawala dan pengetahuannya masing-masing individu tentang objek tersebut. Persepsi bersifat subjektif karena bukan sekedar penginderaan, prestasi kita terhadap dunia nyata merupakan olahan semua informasi yang dipengaruhi oleh kondisi psikologis dan pengalaman kita. Maka dapat disimpulkan bahwa persepsi merupakan suatu pandangan atau tanggapan individu terhadap suatu objek yang dipengaruhi oleh pengalaman, proses belajar atau sosialisasi pengetahuan dan cakrwala individu tentang objek tertentu.

Kedua, minat belajar siswa terhadap sebagian besar termasuk dalam kategori baik $(56,55 \%)$. Minat belajar siswa berpengaruh positif $\left(b_{2}=0,590\right)$ dan signifikan $\left(t_{\text {hitung }}>t_{\text {tabel }}\right)$ terhadap prestasi belajar siswa. Apabila minat belajar siswa terhadap Bahasa Indonesia bertambah baik maka prestasi belajar siswa juga baik begitu pula sebaliknya apabila minat belajar siswa kurang baik maka prestasi belajar juga kurang. Minat besar pengaruhnya terhadap belajar, karena bila bahan pelajaran yang dipelajari tidak sesuai dengan minat, siswa tidak akan belajar dengan sebaik-baiknya, karena tidak ada daya tarik baginya. Siswa tidak akan bersunggu-sungguh belajar sehingga tidak memperoleh kepuasan dari pelajaran itu. Bahan pelajaran yang menarik minat siswa, lebih mudah dihafalkan dan disimpan, karena minat menambah kegiatan belajar. Minat merupakan salah satu faktor yang dapat mempengaruhi belajar dan hasilnya maka minat dapat mempengaruhi kwalitas pencapaian hasil belajar siswa dalam bidang-bidang tertentu. Minat belajar yang besar cenderung menghasilkan prestasi yang tinggi, sebaliknya minat belajar yang kurang akan menghasilkan prestasi yang rendah. Maka apabila seorang siswa mempunyai minat yang besar terhadap suatu bidang studi ia 
akan memusatkan perhatian lebih banyak dari temannya, kemudian karena pemusatan perhatian yang intensif terhadap materi itulah yang memungkinkan siswa tadi untuk belajar lebih giat, dan akhirnya mencapai prestasi yang tinggi dalam bidang studi tersebut.

Ketiga, motivasi belajar siswa terhadap Bahasa Indonesia sebagian besar termasuk dalam kategori baik (74,40\%). Motivasi belajar siswa berpengaruh positif $\left(b_{3}=0,473\right)$ dan signifikan $\left(\mathrm{t}_{\text {hitumg }}>\mathrm{t}_{\text {tabel }}\right)$ terhadap prestasi belajar siswa. Apabila motivasi belajar siswa terhadap Bahasa Indonesia bertambah baik maka prestasi belajar siswa juga baik begitu pula sebaliknya apabila motivasi belajar siswa kurang baik maka prestasi belajar juga kurang. Motivasi sangat terkait dalam belajar, dengan motivasi inilah siswa menjadi tekun dalam proses belajar, dengan motivasi juga kualitas hasil belajar siswa kemungkinan dapat diwujudkan. Siswa yang dalam proses belajar bidang studi Bahasa Indonesia mempunyai motivasi yang kuat dan jelas, pasti akan tekun dan berhasil belajarnya. Hal itu disebabkan karena ada tiga fungsi motivasi yaitu, mendorong manusia untuk berbuat dan melakukan aktivitas, menentukan arah perbuatannya, serta menyeleksi perbuatannya. Sehingga perbuatan siswa senantiasa selaras dengan tujuan belajar yang akan dicapainya.

\section{SIMPULAN DAN SARAN}

Simpulan yang dapat ditarik dari penelitian yang telah dilakukan adalah sebagai berikut. Pertama, terdapat hubungan yang positif dan signifikan antara persepsi siswa terhadap guru Bahasa Indonesia dengan prestasi belajar siswa semester 2 kelas VIII MTsN 3 Gunungkidul dengan koefisiensi korelasi sebesar 0,544 . Kedua, terdapat hubungan yang positif dan signifikan antara minat belajar siswa untuk mempelajari pelajaran Bahasa Indonesia dengan prestasi belajar siswa semester 2 kelas VIII MTsN 3 Gunungkidul dengan koefisiensi korelasi sebesar 0,556. Ketiga, terdapat hubungan yang positif dan signifikan antara motivasi belajar siswa untuk mempelajari pelajaran Bahasa Indoensia dengan prestasi belajar siswa semester 2 kelas VIII MTsN 3 Gunungkidul dengan koefisiensi korelasi sebesar 0,565.
Keempat, terdapat hubungan yang positif dan signifikan antara persepsi siswa terhadap guru Bahasa Indonesia, minat belajar dan motivasi belajar siswa untuk mempelajari Bahasa Indonesia dengan prestasi belajar siswa semester 2 kelas VIII MTsN 3 Gunungkidul dengan koefisiensi korelasi sebesar 0,678.

Berdasarkan hasil penelitian yang diperoleh maka disarankan beberapa hal sebagai berikut. Pertama, bagi guru di MTsN 3 Gunungkidul lebih memperhatikan persepsi siswa terhadapanya dengan meningkatkan kualitas dalam mengajar maupun berkomunikasi terhadap siswa baik didalam maupun luar kelas. Kedua, bagi orang tua hendaknya mendukung dan mengarahkan anaknya dalam belajar dengan meningkatkan motivasi dan minat belajar siswa terutama pada pelajaran Bahasa Indonesia dengan memberikan dorongan, penghargaan maupun mengikutsertakan siswa untuk mengikuti bimbingan belajar. Ketiga, penelitian lebih lanjut disarankan agar penelitian ini dikembangkan dengan menggunakan variabel lain dan melengkapi dengan wawancara supaya hasilnya lebih mendalam (in-depth).

\section{DAFTAR PUSTAKA}

Anderson, A. H. \& Kyprianou, A. (1994). Effective Organizational Behaviour. Massachusetts, USA: Blackwell.

Arikunto, S. (2002). Prosedur Penelitian, Suatu Pendekatan Praktek., Jakarta: Rineka Cipta.

Deporter, B., Reardon, M. \& Nourie S. (2001). Quantum Teaching: Mempraktikkan Quantum Learning di Ruang-Ruang Kelas. Bandung: Kaifa

Gujarati, D. (1995). Ekonometrika Dasar. Terjemahan Sumarno Zain. Jakarta: Erlangga.

Usman,H. (2004). Manajemen Pendidikan. Yogyakarta: Pascasarjana UNY

Joni, R.T. (1991). "Pokok-pokok Pikiran Mengenai Pendidikan Guru". Dalam Soedijarto \& Cony R. Semiawan (Ed). Mencari Strategi Pengembangan Pendidikan Nasional Menjelang Abad XXI. Jakarta: PT Grasindo. 
Lawson, A.E. (1995). Sciece Teaching and the Development of Thinking, California: Wadworth Publishsing Company.

Leong, L. (2005). Improving Students' Interest in Learning: Some Positive Techniques, Central Connecticut State University, Information and Learning Company.

Mantra, I.B. \& Kasto. (1989). Penentuan Sampel. Dalam Singarimbun, M. \& Soffian Effendi . Metode Penelitian Survei. Jakarta: LP3ES.

Notoatmodjo, S. (1997). Pendidikan dan Perilaku Kesehatan. Jakarta: Renika Cipta.

Nurgiyantoro, B. (2002). Statistik Terapan untuk Penelitian Ilmu-Ilmu Sosial. Yogyakarta: Gadjah Mada University Press.
Singarimbun, M. \& Effendi, S. (1989). Metode Penelitian Survei, Jakarta: LP3ES

Sudjana. (1991). Metoda Statistika. Bandung: Tarsito.

Sugiyono. (2005). Statistika untuk Penelitian. Bandung: Alfabeta

Sugiyono. (2004). Metode Penelitian Bisnis. Bandung: Alfabeta

Suryabrata, S. (2005). Psikologi Pendidikan. Jakarta: Rajawali Press

Timpe, D.(1991). Memotivasi Pegawai. Jakarta: Elexmedia Komputindo Gramedia.

Wahono dan Rusmiyanto. (2004). Kreatif Berbahasa dan Bersastra Indonesia. Bandung: Ganeca Exact. 